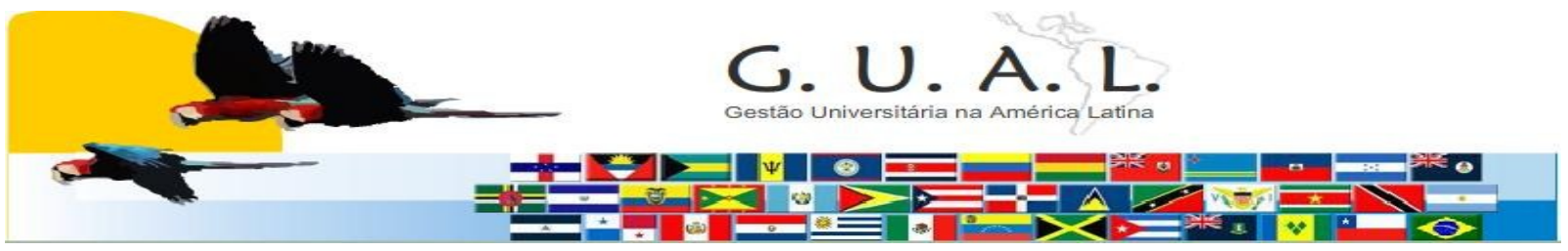

ISSN 1983-4535

\title{
PRESSUPOSTOS DA COGNIÇÃO E AS FERRAMENTAS DA WEB 2.0: ASPECTOS RELEVANTES NO PROCESSO DE GESTÃO DE IES PRIVADA
}

Thiago Henrique Almino Francisco, Especialista Universidade Federal de Santa Catarina - UFSC thiagohaf@engeplus.com.br

Emillie Michels, Especialista

Universidade Federal de Santa Catarina - UFSC emillie@fucap.edu.br

\author{
Expedito Michels, Especialista \\ Universidade Federal de Santa Catarina - UFSC \\ expedito@fucap.edu.br
}

\author{
Alexandre Moraes Ramos, Doutor \\ Universidade Federal de Santa Catarina - UFSC \\ amrrms@gmail.com
}

\section{RESUMO}

Este trabalho preleciona contextualizar de que modo as interações cognitivas podem facilitar a utilização das ferramentas da Web 2.0 no processo de gestão de uma instituição de ensino privada, auxiliando a construção de uma epistemologia gerencial às instituições que atuam neste segmento. A digressão teórica elenca aspectos relacionados à epistemologia da cognição e seus pressupostos, além dos conceitos que se voltam a compreensão do ensino superior privado e da avaliação institucional como método de construção de uma identidade institucional e, ainda, quanto à utilização das ferramentas da Web 2.0 na fundamentação deste processo. Para tanto, será desenvolvida uma pesquisa acadêmica, aplicada, baseada na documentação direta configurando-se como uma pesquisa básica e, quanto aos objetivos, classificada como exploratória, predominantemente qualitativa, classificando-se como uma pesquisa-ação. Para a coleta de dados serão consideradas as bases voltadas à pesquisa estruturada. Os resultados permitem concluir, entre outros aspectos, que interações cognitivas facilitam a utilização das ferramentas da Web 2.0, pois que permitem a construção do conhecimento gerencial a uma reflexão orientada pelos membros de seu corpo social da instituição em busca de uma epistemologia a partir de processos vinculados à conscientização de seu corpo social.

Palabras-chave: Cognição. Ensino superior. Web 2.0. 


\section{PRESSUPOSTOS DA COGNIÇÃO E AS FERRAMENTAS DA WEB 2.0: ASPECTOS RELEVANTES NO PROCESSO DE GESTÃO DE IES PRIVADA}

\section{INTRODUÇÃO}

A construção do conhecimento fundamentado nas interações de procedimentos que alicerçam a aprendizagem permite a observância de evidências relevantes ao processo de reflexão construtivista arrolada ao entendimento da realidade do pensamento gerencial. Sob a orientação destes aspectos, a utilização destes princípios promove o entendimento dos critérios necessários à estruturação de uma epistemologia, sobretudo por meio da discussão dos envolvidos na estruturação de processos disruptivos no ensino superior, alinhando as atividades que consolidam a aprendizagem pedagógica e gerencial.

Por meio destes pressupostos, é importante compreender a relação destas premissas com a construção de uma identidade institucional, sobretudo em função da necessidade da edificação de conhecimentos e da reflexão que se volta a abarcar o entorno acadêmico. Porém, nesse contexto, buscam-se indicativos paliativos que permitam o desenvolvimento dessas entidades, especificamente pautados nos resultados imediatos, negligenciando as premissas que visam consolidar a indissociabilidade entre ensino, pesquisa e extensão.

Para entender este processo, Brasil (2004a) implantou um método responsável por orientar a construção da identidade institucional, bem como a oferta dos programas de ensino no âmbito superior a partir de uma reflexão sistemática pautada na estrutura acadêmica, pedagógica e administrativa desse tipo de organização, conhecida como Avaliação Institucional. Desse modo, tal reflexão é consubstanciada pela atuação dos membros do corpo social da instituição, os quais tem a função de construir e disseminar todo o tipo de conhecimento vinculado a perenidade dessas organizações.

No bojo destas orientações, fundem-se atividades e ferramentas que busquem o compromisso destes agentes na participação e na elucidação de problemáticas vinculadas a compreensão da realidade institucional. Assim sendo, em função das novas perspectivas que orientam a expansão do ensino neste segmento, busca-se consolidar a utilização de mecanismos que promovam uma relação direta com o público-alvo dessas organizações, inserindo-os nas discussões que visem consolidar uma epistemologia gerencial aplicada a este segmento de ensino, respeitando os procedimentos de construção da aprendizagem.

A partir destas considerações e ponderando sobre as novas tecnologias no âmbito do ensino, as ferramentas da Web 2.0 preconizam premissas construtivas a partir de interações 


\section{PRESSUPOSTOS DA COGNIÇÃO E AS FERRAMENTAS DA WEB 2.0: ASPECTOS RELEVANTES NO PROCESSO DE GESTÃO DE IES PRIVADA}

cognitivas dinâmicas, mormente evidenciadas no processo de construção de conhecimento voltado à compreensão institucional.

\section{CONTRIBUIÇÕES TEÓRICAS}

\subsection{Epistemologia da cognição}

A gênese do termo cognição, que fundamenta seus aspectos epistemológicos, alicerçase nas contribuições de Aristóteles e Platão e se traduz em aspectos relacionados ao processo de aprendizagem. Sob a égide desses aspectos, Fialho (2006) atrela o termo às ciências comportamentais, sobretudo à Psicologia, tendo em vista seus aspectos metodológicos, de compreensão e resolução de problemas por meio de associação biológicas e comportamentais. Assim sendo, as evidências cognitivas passam a ser enfáticas no processo de construção do conhecimento aplicado no âmbito da expansão organizacional de qualquer organização.

Santos (2008) considera a cognição como uma habilidade humana que pode ser desenvolvida ao passo do valor agregado pelas competências. Nesse vértice de entendimento, os conhecimentos, habilidades e atitudes vinculados à construção do conhecimento promovem a fundamentação intelectual no bojo das ações que preconizam o domínio da ciência, tornando-se fator preponderante no desenvolvimento e na expansão das organizações amparadas pelo conhecimento.

Fachin et al (2009) debatem o marco orientador do processo de expansão das organizações a partir da importância da compreensão das ações do indivíduo na sistemática aplicada à constituição do novo ambiente organizacional. Assim sendo, com base nas exposições dos autores, fundamentam-se as premissas que corroboram a participação do ser humano na construção da identidade organizacional, em qual o impacto dessas ações alicerçam os métodos investigativos que envolvem o manuseio das informações no ambiente. Neste contexto, o processo cognitivo acontece a partir da utilização de práticas que colimam a estrutura gerencial da organização aos aspectos vinculados ao processo de aprendizagem, confirmando a percepção de Bloom (et al, 1973) ao citar a relevância dos objetivos cognitivos no processo de estruturação do conhecimento aplicado na organização.

A partir dessa discussão, a percepção de Richard (apud SANTOS, 2008) confirma que o indivíduo inserido na organização está exposto aos métodos de aquisição de conhecimento, sustentados por formas de transformação de informação que proporcionam a aprendizagem

Rev. GUAL., Florianópolis, v.4, n. 1, p.01-26, jan/abr. 2011 


\section{PRESSUPOSTOS DA COGNIÇÃO E AS FERRAMENTAS DA WEB 2.0: ASPECTOS RELEVANTES NO PROCESSO DE GESTÃO DE IES PRIVADA}

pela descoberta, no qual o conhecimento tácito é construído a partir de informações procedurais que são aplicadas à resolução de problemas, e pelo texto, no qual o conhecimento perpassa a compreensão de informações simbólicas, resultando em habilidades declarativas explicítas.

Sob essa orientação, o indivíduo passa a se transformar em um agente ativo no processo de disseminação de conhecimento a partir de suas capacidades intelectuais estruturadas por meio do manejo da informação. Neste entendimento, Neves (2006) salienta que os modelos mentais se fundamentam nos métodos sistemáticos de manejo e transformação das informações a partir de atividades cognitivas relacionadas com a percepção, memória, inferência e dedução. Desta maneira, portanto, corroboram a estrutura semântica do processo cognitivo, especificamente pela relação com o pragmatismo de indivíduos proficientes em contato com o processo de aprendizagem.

Em seus aspectos epistemológicos, a cognição preconiza a construção de ambientes de aprendizagem, os quais passam a servir de instrumentos norteadores para um processo que, segundo Demo (2009), orienta a reflexão, a construção, a desconstrução e a reconstrução do conhecimento, sustentando as ações organizacionais de posicionamento e expansão, bem como todo o processo de aprendizagem baseada na estruturação do conhecimento.

Desse modo, em seus aspectos epistemológicos, a cognição é responsável por determinar os aspectos que balizam o processo de aprendizagem que, conforme Anderson (et al, 2001), pode ser compreendido a partir da relação entre cinco dimensões do conhecimento e seis termos que permitem formular os objetivos do processo de aprendizagem.

Gil (2009), com base nas assertivas de Anderson (et al, 2001), define esses conhecimentos a partir da orientação sobre o conhecimento factual que é focado especificamente em processos baseados em terminologias, detalhes e elementos; mitra o conhecimento conceitual, especificamente atrelado aos processos de classificação, a princípios e generalizações e as teorias, modelos e estruturas. Refere-se, ainda, ao conhecimento procedural, que se relaciona com métodos e técnicas e critérios para a adoção de procedimentos e ao conhecimento metacognitivo, caracterizado pelas ações de conhecimento estratégico vinculadas à compreensão do processo cognitivo e ao autoconhecimento.

Rev. GUAL., Florianópolis, v.4, n. 1, p.01-26, jan/abr. 2011 


\section{PRESSUPOSTOS DA COGNIÇÃO E AS FERRAMENTAS DA WEB 2.0: ASPECTOS RELEVANTES NO PROCESSO DE GESTÃO DE IES PRIVADA}

Anderson (et al, 2001) destaca a interdependência destes conhecimentos no processo de relação com os seis aspectos balizadores do processo de aprendizagem, se volta ao processo elencado no Quadro1.

\section{Quadro 1}

Aspectos balizadores do processo de aprendizagem

\begin{tabular}{|c|l|}
\hline \multicolumn{5}{|c|}{ Aspectos balizadores do processo de aprendizagem } \\
\hline Lembrar & $\begin{array}{l}\text { Propõe a construção de objetivos pautados, sobretudo, nos verbos } \\
\text { "reconhecer", "relembrar" e "identificar }\end{array}$ \\
\hline Entender & $\begin{array}{l}\text { Preconiza objetivos por meio dos verbos "interpretar", "exemplificar" e } \\
\text { "comparar", }\end{array}$ \\
\hline Aplicar: & $\begin{array}{l}\text { Construindo objetivos pautados nos verbos "executar", "implementar" e } \\
\text { "utilizar"; }\end{array}$ \\
\hline Analisar & $\begin{array}{l}\text { Estruturando objetivos por meio dos verbos "diferenciar", "organizar" e } \\
\text { "categorizar" }\end{array}$ \\
\hline Avaliar & Designando objetivos relacionados ao verbo "criticar", "julgar" e "decidir"; \\
\hline Criar: & Indicando objetivos relacionados aos verbos "gerar", "planejar" e "produzir". \\
\hline
\end{tabular}

Fonte: Anderson et al, 2001.

A partir da compreensão dessas preposições, sob a orientação de Lima (2003), pode-se inferir que os aspectos epistemológicos da cognição são responsáveis por orientar a interação do indivíduo com a informação, especificamente por meio da construção de ambientes orientados à troca de informações e a construção do conhecimento. Destarte, por meio das inferências de Jacob e Shaw (1998), percebe-se que os aspectos cognitivos são responsáveis pela construção do ambiente social e organizacional das comunidades do conhecimento.

\subsubsection{Pressupostos das Teorias Cognitivas}

Os aspectos epistemológicos da cognição norteiam o processo de construção do conhecimento e servem de pressupostos básicos à constituição das teorias cognitivas. Sob o entendimento desse aspecto e de acordo com Winn e Snyder (1996), a cognição envolve feitios que direcionam a aprendizagem a partir da percepção do indivíduo que aprende, sendo que os resultados obtidos servem de balizadores para o alinhamento de ações baseadas no aprendizado.

Dessa maneira, a construção das teorias cognitivas se fundamenta nas contribuições de Vignaux (1991), ao destacar que o resultado da aprendizagem e da construção de novos conhecimentos perpassa um modelo obsoleto de constituição de novas informações e fixa 


\section{PRESSUPOSTOS DA COGNIÇÃO E AS FERRAMENTAS DA WEB 2.0: ASPECTOS RELEVANTES NO PROCESSO DE GESTÃO DE IES PRIVADA}

uma conjectura baseada na interação de conhecimentos já existentes, corroborando, portanto, as definições de Castaño (1994), que caracterizam as crenças, valores e expectativas do homem a partir da ênfase na troca de conhecimentos necessários à consolidação do processo de aprendizagem.

Winn e Snyder (1996) destacam a relevância dos aspectos que orientam a evolução do processo de aprendizagem, sobretudo a partir da interdependência entre os aspectos cognitivos e as ferramentas tecnológicas atuais. Não raro, os estudos baseados no aprendizado consideram a relação entre a tecnologia e as competências emergentes como um elemento constitutivo da aprendizagem, consolidando a participação do individuo no processo de desenvolvimento do entorno. Neste caso, a partir da contribuição do estudo das ciências computacionais e humanas, o avanço da tecnologia promoveu a construção de novas competências que subsidiam o processo cognitivo.

No âmbito das contribuições de Bednar (et al, 1992), as teorias cognitivas perpassam o processo simples de aprendizagem e consolidam a relação análoga entre tecnologia, qualificação e desenvolvimento humano. Nesse caso, pode-se inferir que estas teorias levam em consideração a interação humana com a sistemática aplicada à resolução de um problema, priorizando a busca por informações e a construção de novas definições.

Sob o broquel dessa assertiva, Coutinho (2005) e Coutinho (2006) ressaltam o fato de que a construção do modelo cognitivo e das teorias que alicerçam esta definição devem considerar a utilização das tecnologias da informação que fundamenta as concepções de aprendizagem orientadas ao resultado. Assim sendo, por meio destas ações, as problemáticas discutidas voltadas ao processo de aprendizagem se baseiam na interação entre a mecanismos de busca de informação e as associações construtivistas elencadas pelo individuo a partir das orientações de Anderson (et al, 2001).

Ao passo da compreensão da transformação das informações e fundamentação do processo de aprendizagem, Pozo (1994) intensifica a definição de que o indivíduo, ao adentrar no âmbito da aprendizagem baseada nas teorias cognitivas, torna-se agente modificador ativo da informação, sendo por ela levado a atividades que inferem de modo direto em seu ambiente. Neste caso, ainda conforme as exposições do autor, esse agente transformador passa a ser considerado um "infomívoro", ao passo de que ele se torna um dependente do processo de conhecimento. 


\section{PRESSUPOSTOS DA COGNIÇÃO E AS FERRAMENTAS DA WEB 2.0: ASPECTOS RELEVANTES NO PROCESSO DE GESTÃO DE IES PRIVADA}

Coutinho (2006) confirma as assertivas de Pozo (2004) e traz à luz a relação interdependente e sistêmica do processo de aprendizagem configurado a partir do processo cognitivo, considerando os métodos processuais de aquisição e transformação de conhecimento por meio do recebimento da informação - input, a organização dos dados processing, o que é devidamente retido - storage, e o que é construído por esta relação retrieval. Neste caso, especificamente, o processo de aprendizagem se configura por meio de uma abordagem sistêmica, tendo um status de procedimento estratégico de construção de conhecimento direcionado a uma finalidade.

Por sua vez, com base nas inferências de Clark e Sugrue (1991) o conhecimento por si só não traz beneficio sem uma finalidade aplicativa ou sem uma sistemática de construção alicerçada por condições de aprendizagem específicas. Neste caso, portanto, as teorias cognitivas que orientam o processo de aprendizagem se fundamentam nos aspectos que se voltam à aderência da realidade na qual a hipótese está inserida e as ferramentas utilizadas para a busca de informação e a construção do conhecimento. Assim sendo, conforme Clark e Sugrue (1991), os paradigmas elencados no processo de investigação e construção das teorias cognitivas culminam assertivas relacionadas à alteração do foco investigativo de uma concepção de aprendizagem centrada no ensino para uma intuição centrada na resolução dos questionamentos e à mudança da perspectiva, consolidando a reciprocidade interativa entre os estímulos externos provocados pela ânsia do conhecimento.

Coutinho (2008) ainda evidencia estes princípios ao discutir e posicionar as teorias cognitivas no cerne dos métodos de aprendizagem, corroborando as definições e problemáticas que se direcionam a compreensão dos métodos e técnicas de aprendizagem e alavancam o processo de construção do conhecimento baseado na interação entre a tecnologia e a sistemática de resolução dos problemas baseadas em novas competências, sobretudo as cognitivas.

\subsection{O ensino superior privado no Brasil}

Por meio das inferências de Francisco (et al, 2009), o ensino superior privado no Brasil se tornou uma ferramenta amplamente disseminada e eficaz para o desenvolvimento das competências intelectuais e de formação profissional no País, sobretudo, em função da conotação de status, pelos métodos de formação do padrão moral, intelectual, acadêmico e, 


\section{PRESSUPOSTOS DA COGNIÇÃO E AS FERRAMENTAS DA WEB 2.0: ASPECTOS RELEVANTES NO PROCESSO DE GESTÃO DE IES PRIVADA}

claro, profissional desenvolvidos por estas organizações. Entretanto, esse segmento de ensino vem caindo em descrédito em detrimento da falta de alinhamento estratégico das instituições responsáveis por sua expansão e da dificuldade de posicioná-las frente às necessidades do mercado.

Baseado nestes acontecimentos, Machado (2008) discute a eficácia do posicionamento mercadológico das IES privadas no Brasil. O autor destaca que, em virtude da alta oferta de programas vinculados ao ensino superior, os gestores acadêmicos não preconizaram um alicerce que sustente o padrão de qualidade esperado pelo mercado, sobretudo, em virtude da falta de uma métrica de desempenho e da subjetividade nos critérios para avaliar o posicionamento das instituições.

Ainda por Machado (2008, p. 19), atualmente “propõe-se uma nova estruturação interna para que haja condições de medições mais precisas e individuais e para que possa haver gestão dirigida (focada)". E isso, como forma de recomendar um melhor posicionamento e abrangência dos programas acadêmicos, aos quais devem atingir seu público-alvo e gerar benefícios para o meio no quais estas se inserem.

Assim sendo, com base nos indicativos das pesquisas institucionais que estudam a evolução do ensino superior no Brasil, publicadas pelo Instituto de Pesquisas Educacionais Anísio Teixeira - INEP, é possível identificar a aderência entre os dados disponíveis e as assertivas de Garcia (2006) ao criticar os dados pesquisados e elencar alguns pontos fundamentais no âmbito do ensino superior, nos quais destacam-se, sobretudo, o fato de que público-alvo das IES possui um maior número de ferramentas de informação e seus hábitos acadêmicos mudam com frequência. Atenta-se, ainda, para os fatores relacionados à queda na fidelidade, principalmente pelo fato da alteração do perfil do acadêmico, o que pode representar um perigo para as IES antigas e uma oportunidade para as novas ou emergentes a evasão é um sinal de infidelidade e a curva de desenvolvimento do setor da educação, que já está entrando no processo de declínio.

No bojo dessa compreensão, há que se salientar que também ocorre uma grande redução no tempo de ciclo de vida dos produtos - os cursos diminuíram (tecnólogos e sequenciais) e é considerável a incidência de novos players no mercado, com qualidade perceptível e com preço baixo. Desse modo, inferindo diretamente nos custos para a captação de novos alunos, sobretudo nos publicitários, que tornaram se cada vez maiores.

Rev. GUAL., Florianópolis, v.4, n. 1, p.01-26, jan/abr. 2011 


\section{PRESSUPOSTOS DA COGNIÇÃO E AS FERRAMENTAS DA WEB 2.0: ASPECTOS RELEVANTES NO PROCESSO DE GESTÃO DE IES PRIVADA}

Ao se compreender o contexto do exposto, percebe-se a partir das inferências de Inep (2009) que as políticas públicas para o ensino superior brasileiro, principalmente no âmbito privado, devem considerar as metas elencadas no Plano Nacional de Educação: a inserção de $30 \%$ dos acadêmicos inseridos na faixa etária considerada como o público-alvo das instituições, que compreende os jovens entre 18 e 24 anos. Entretanto os esforços empreendidos no último decano apresentam um retrato desfavorável se consideramos que apenas 13\% dos jovens considerados pelo Documento estão devidamente inseridos no ensino superior. Assim sendo, configura-se o fato de que as mudanças ambientais, macro e micro econômicas e estruturais devem ser plenamente compreendidas para que as estratégias corretas sejam desenvolvidas e implementadas.

Baseado nessas inferências, a comunidade acadêmica deve atentar para o processo de expansão orientada, a partir da ação da livre iniciativa já que ela, de acordo com os dados de Inep (2009), é a responsável por aproximadamente 75\% das matrículas, sendo que a grande maioria destes acadêmicos está inserida no contexto das instituições credenciadas como faculdades isoladas, escolas ou institutos superiores de educação. Deve-se destacar ainda que a livre iniciativa configura-se como a principal responsável pela expansão do ensino superior no Brasil já que suas atividades atingiram níveis elevados de crescimento nos últimos 15 anos, sobretudo a partir das políticas de democratização do ensino propagadas pelos órgãos reguladores e pelas instâncias governamentais que construíram métodos, roteiros e manuais próprios à atividade destas instituições. Contudo, em função da falta de orientação e esclarecimento frente às políticas regulatórias do ensino, o cenário encontra-se marcado pela expansão desenfreada das instituições privada.

A partir deste crescimento estabeleceu-se o "mercantilismo acadêmico" considerado por Ristoff (2009) e que se configurou a partir da abnegação dos aspectos qualitativos pelas instituições e da falta de pesquisas em relação às melhores práticas aplicadas ao ensino superior. Neste contexto, fica clara a necessidade de se buscar uma definição dos processos de gestão voltados às instituições privadas, sobretudo a partir de associações cognitivas que consolidem as definições profícuas da atividade acadêmica desenvolvida pela livre iniciativa.

Em função do fato, as diversas práticas de gestão desenvolvidas nas instituições privadas do país deveriam preconizar a busca pela eficiência nos processos e observar conceitos e aspectos voltados ao público-alvo e aos demais fatores inerentes à instituição, 


\section{PRESSUPOSTOS DA COGNIÇÃO E AS FERRAMENTAS DA WEB 2.0: ASPECTOS RELEVANTES NO PROCESSO DE GESTÃO DE IES PRIVADA}

como na contribuição que segue. Em função destes métodos de gestão, no Gráfico 1, Braga (2005) apresenta uma análise de cenário que identifica a necessidade da aplicação de modelos de gestão que assegurem a sobrevida das instituições em um futuro próximo.

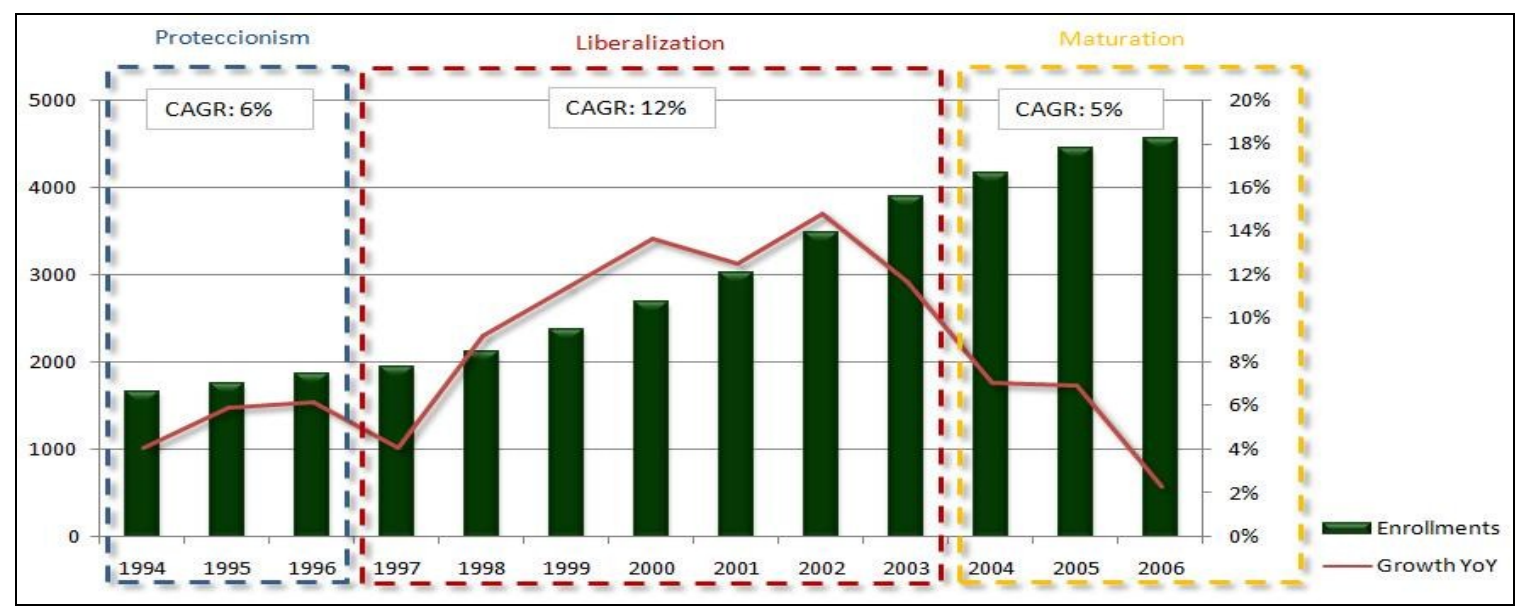

Gráfico 1: Análise da perspectiva para o ensino superior

Fonte: Braga, 2005.

Silva (2008) corrobora as assertivas de Ristoff (2009) e Garcia (2006) ao destacar o fato da ampla concorrência enfrentada pelas instituições em virtude dos novos entrantes, do ensino a distância e das novas modalidades emergentes da educação. Neste sentido, as instituições de ensino superior se vêem obrigadas a agregar valor em suas ações a partir das especificidades do mercado no qual estão inseridas. Todavia, em função desta necessidade, elas se deparam com gestores mal preparados e que não buscam a capacitação necessária para tal desenvolvimento. Desse modo, não logram o êxito esperado em suas ações pelo fato da ausência de conhecimento que balizam os processos de mudança aplicados à instituição.

A partir destes registros, percebe-se que a sobrevivência das instituições privadas neste mercado competitivo deve obedecer alguns pontos diretamente relacionados à consolidação de seus processos gerenciais. Desse modo, elencados por Garcia (2006), esses pontos compreendem na criação de uma estrutura baseada na inteligência competitiva e em processos estratégicos, no desenvolvimento de uma estrutura focada na utilização da tecnologia e na observância aos processos reguladores e voltados à compreensão da legislação educacional para o ensino superior.

Neste contexto, a construção da epistemologia do ensino superior perpassa pela relação intrínseca e interdependente destes três pontos, salientando que a utilização da 


\section{PRESSUPOSTOS DA COGNIÇÃO E AS FERRAMENTAS DA WEB 2.0: ASPECTOS RELEVANTES NO PROCESSO DE GESTÃO DE IES PRIVADA}

tecnologia elenca estruturas cognitivas que permitem que o corpo social da instituição possa entender o seu contexto e atuar de modo a compreender as anuências de seu processo gerencial, tal qual corroborado no texto que segue:

Pode-se dizer que a dificuldade em se administrar a universidade é antes de tudo um reflexo da dificuldade de administrar uma organização qualquer. Aqueles que a administram, baseados em teorias e modelos de gestão desconhecem que a própria empresa não é equilíbrio, mas desequilíbrio. Não é estabilidade, mas instabilidade. Não é harmonia, mas conflito. Não é simplicidade, mas complexidade. Logicamente, se há problemas de se entender essas questões nas empresas, haverá problemas também quando se aplicar os preceitos empresariais na universidade. Afinal, não é só a universidade que é complexa, conflituosa. (SCHLICKMANN, 2009, p. 14)

Sob a orientação destes pressupostos, portanto, a construção do conhecimento no âmbito acadêmico permite compreender que a gestão e a expansão de uma instituição privada estão atreladas a utilização de métodos cognitivos de construção de conhecimento e geração de aprendizagem no âmbito da instituição e que se fundamenta nas contribuições da Avaliação Institucional e, de acordo com Demo (2009), pela utilização das ferramentas da Web 2.0.

\subsubsection{A Avaliação Institucional no Ensino Superior Privado}

Preconizada por Brasil (2004b), a Avaliação Institucional é considerada um processo transformador no patamar qualitativo da Educação Superior. Ele é consolidado a partir de instrumentos que qualifiquam os processos de sustentação da qualidade no sistema da educação superior. E assim, construindo subsídios fundamentais para o desenvolvimento das atividades acadêmicas no âmbito dos cursos de graduação.

Pelas assertivas de Francisco (et al, 2009), que se esmeram às abordagens de Brasil (2004a), o Sistema Nacional de Avaliação da Educação Superior (SINAES) se desenvolve sob a orientação de uma concepção baseada no compromisso com a qualificação e a relevância das atividades educacionais. Desse modo, confirmando esta concepção, Brasil (2004b) apresenta procedimentos metodológicos para a Avaliação das instituições de educação superior que são pautados na Avaliação das Instituições de Educação Superior (AVALIES); Avaliação dos Cursos de Graduação (ACG); Avaliação do Desempenho dos Estudantes (ENADE). Tais procedimentos permitem às instituições, em função do caráter sistemático da 


\section{PRESSUPOSTOS DA COGNIÇÃO E AS FERRAMENTAS DA WEB 2.0: ASPECTOS RELEVANTES NO PROCESSO DE GESTÃO DE IES PRIVADA}

avaliação, concatenar seus objetivos estratégicos e indicadores aos processos avaliativos preconizados às suas atividades.

Baseado nestes pressupostos, Schlickmann (2009) salienta que o processo avaliativo promove critérios que consubstanciam a construção de uma epistemologia direcionada ao ensino superior, considerada ponto profícuo no processo de consolidação da oferta e da expansão acadêmica no Brasil. Desse modo, a avaliação infere sobre as estrutura cognitivas dos agentes institucionais, promovendo associações que configuram o processo de construção do conhecimento e aprendizagem preconizados nas instituições, mormente considerando as privadas.

A partir da orientação destes processos, os resultados passam a ser considerados como insumos estratégicos e norteadores da ação acadêmica perante as autarquias do Ministério da Educação. Os resultados dos procedimentos, neste contexto, passam a orientar as ações de crescimento institucional, servindo de insumos que colimam o processo de expansão institucional e permitem a percepção da identidade institucional considerada elementar no processo de posicionamento mercadológico destas organizações. Desse modo, em decorrência de sua concepção, Brasil (2004a, p. 13) salienta que:

todo o processo está orientado para a expansão da oferta, para o aumento permanente de sua eficácia institucional, da sua atividade acadêmica e social e especialmente do aprofundamento dos compromissos e responsabilidades sociais.

Sob esta concepção, os indicativos metodológicos instituídos pelos órgãos reguladores do ensino superior brasileiro são considerados incoerentes à realidade das instituições privadas, mormente pela contradição instituída em atos documentais ao incitar a construção da identidade das instituições. Este ponto fica explícito ao identificar os pontos considerados inconstitucionais descritos na a Portaria Normativa n. 12, de 5 de setembro de 2008, que institui o Índice Geral de Cursos de Graduação aferido pelo calculo do Conceito Preliminar de Curso que, em seus aspectos, a partir da Portaria Normativa n. 821, de 24 de agosto de 2009, passa a considerar o peso de $20 \%$ sobre os professores com o título de Doutor, contribuindo para a insatisfação das instituições privadas.

Neste contexto, os aspectos que causam insatisfação das instituições privadas se arrolam ao fato de que os roteiros avaliativos não preconizam o devido respeito à identidade

Rev. GUAL., Florianópolis, v.4, n. 1, p.01-26, jan/abr. 2011 


\section{PRESSUPOSTOS DA COGNIÇÃO E AS FERRAMENTAS DA WEB 2.0: ASPECTOS RELEVANTES NO PROCESSO DE GESTÃO DE IES PRIVADA}

institucional, o que acarreta falhas no processo de implantação deste processo. Porém, mesmo com as falhas identificadas no método, o desenvolvimento da avaliação promove uma relação direta com os stakeholders da instituição, promovendo uma linha de indicadores restrita, porém determinantes na metodologia de consolidação desta organização no mercado.

Em virtude do que é identificado e proposto pela avaliação, Silva (2008) tem a avaliação como um processo investigativo e que orientam as atividades das instituições de ensino superior no âmbito privado. Portanto, este processo permite as IES consolidarem os parâmetros de desenvolvimento de seus indicadores e atributos estratégicos, permitindo a atuação de modo a desenvolver suas competências essenciais e atingir seu público-alvo com eficiência.

\subsubsection{Os agentes ativos da Avaliação Institucional}

A construção do conhecimento na instituição perpassa pela contribuição dos diversos agentes ativos que deve ser considerados pelo corpo dirigente da instituição. Neste caso, Brasil (2004a) salienta que este processo promove a consolidação da atuação institucional, sobretudo pelo fato da orientação da oferta do ensino gerada a partir do estudo dos indicadores construídos no processo de investigação na instituição.

Desta maneira:

a avaliação institucional funda-se nos pressupostos desenvolvidos por Stake (1982) quando discute métodos de avaliação capazes de desenvolver a autonomia da instituição, pela participação de todos os segmentos que nela atuam. Este método favorece a autocrítica pela interpretação de problemas e a recomendação de medidas a serem tomadas para o aprimoramento institucional. (ACAFE, 2005, p.4)

Sob a égide das orientações legais, os pressupostos avaliativos devem estar diretamente relacionados com a investigação metodológica no contexto institucional, tal qual afirma Silva (2008), corroborando as premissas de Brasil (2004b), ao salientar a relevância da contribuição de acadêmicos, professores, colaboradores e sociedade a partir de instrumentos de pesquisas devidamente direcionados aos objetivos institucionais. Desse modo, a partir de ações e discussões integradas, a Avaliação Institucional deve contar com a participação democrática destes agentes, considerados por Inep (2009) como o corpo social da instituição ou ainda, conforme Brasil (2004a), comunidade acadêmica. 


\section{PRESSUPOSTOS DA COGNIÇÃO E AS FERRAMENTAS DA WEB 2.0: ASPECTOS RELEVANTES NO PROCESSO DE GESTÃO DE IES PRIVADA}

Conforme Brasil (2004b) as ações dos agentes membros da comunidade acadêmica devem ser orientadas pelas ações de uma comissão responsável por estruturar o processo metodológico da avaliação. Esta comissão, denominada de Comissão Própria de Avaliação, deve ser composta de agentes que compõem o processo de construção cognitiva, sobretudo pelas ações de ensino e aprendizagem. Desta forma:

cada instituição de ensino superior, pública ou privada, constituirá Comissão
Própria de Avaliação - CPA, no prazo de 60 (sessenta) dias, a contar da
publicação desta Lei, com as atribuições de condução dos processos de
avaliação internos da instituição, de sistematização e de prestação das
informações solicitadas pelo INEP, obedecidas as seguintes diretrizes: I -
constituição por ato do dirigente máximo da instituição de ensino superior,
ou por previsão no seu próprio estatuto ou regimento, assegurada a
participação de todos os segmentos da comunidade universitária e da
sociedade civil organizada, e vedada a composição que privilegie a maioria
absoluta de um dos segmentos. (BRASIL, 2004a, p. 2)

No entanto, no decorrer dos anos, a sistemática da avaliação nas instituições, sobretudo nas privadas, não lograram o êxito necessário no processo de inserção destes agentes no contexto do posicionamento institucional. Isso se deu pelo fato das incoerências do processo que são perceptíveis em diversas instituições, pela falta de conhecimento dos gestores institucionais sobre o perfil deste público e, mormente, em virtude da falta de inovações técnicas e metodológicas que preconizam o envolvimento destes agentes. Neste caso, tal fato configura a falha na construção das associações cognitivas no âmbito da instituição, em virtude da dificuldade de se construir um conhecimento que proporcionaria um entendimento dos processos organizacionais na instituição e que pode ser re-orientado a partir da utilização das ferramentas da Web. 2.0, tal como afirma Demo (2009).

\subsection{A web 2.0: ferramentas inerentes à estruturação cognitiva para o ensino}

Ao passo da compreensão do processo de estruturação e posicionamento de uma instituição de ensino superior que atua no mercado da livre iniciativa, a observância de alguns aspectos relacionados ao processo de construção do conhecimento na instituição é fundamental para que o pleno cumprimento do seu papel possa ser perceptível aos olhos da comunidade. Neste contexto, os processos avaliativos que vão orientar a gestão institucional devem contar com a participação dos agentes inseridos no âmbito da instituição, tal como

Rev. GUAL., Florianópolis, v.4, n. 1, p.01-26, jan/abr. 2011 


\section{PRESSUPOSTOS DA COGNIÇÃO E AS FERRAMENTAS DA WEB 2.0: ASPECTOS RELEVANTES NO PROCESSO DE GESTÃO DE IES PRIVADA}

elenca Brasil (2004b), os quais devem depositar suas inferências cognitivas no processo de construção da identidade desta organização.

No entanto, nos tempos contemporâneos, Garcia (2006) afirma que, pelo fato dos gestores não conhecerem os métodos de gerenciamento e as especificidades do mercado do ensino superior, não logram o êxito necessário no processo de construção de conhecimento no âmbito da instituição, sobretudo por não conseguirem o comprometimento profícuo dos membros do corpo social acadêmico nos processos avaliativos. Deve-se salientar ainda que as incoerências metodológicas descritas nas atualizações dos instrumentos de avaliação preconizados pelos órgãos reguladores contribuem para dificultar a construção deste entendimento.

Sob estes aspectos, Demo (2009) salienta que as ferramentas da WEB 2.0 podem ser consideradas um beneficio, em função da possibilidade de interagir as instituições cognitivas do corpo social da instituição em prol da construção do conhecimento necessário a todo o corpo social desta organização. Baseado nestes pressupostos, Demo (2009) destaca que as ferramentas da WEB. 2.0 promovem uma associação cognitiva no âmbito da instituição, permitindo que sua identidade seja construída sob a orientação das discussões autopoiéticas, maiêuticas e hermenêuticas, desenvolvidas no âmbito de sua estrutura. Desse modo, assim como enfatiza Edelman e Tononi (2000), estas interações determinam uma dinâmica disruptiva responsável por gerar práticas autorais, a partir de associações cognitivas que se voltam a construir uma epistemologia institucional, consolidando um newtworking relevante ao processo dinâmico de aprendizagem a partir das redes virtuais na organização.

A partir das orientações de Manson e Rennie (2004) fica claro o fato de que a Web 2.0, no bojo de suas ferramentas, é um instrumento profícuo voltado a fundamentar a participação do agente que interage no contexto institucional. Assim sendo, com base nas orientações de Brow e Duguid (2000), Carliner e Shank (2008) e Saviani (2005), as ferramentas da Web 2.0 preconizam premissas construtivas, a partir de interações cognitivas dinâmicas, sobretudo no processo de construção de conhecimento voltado à compreensão institucional. Destarte, basta a instituição estabelecer seus métodos de conscientização aplicados ao corpo social e em relação às ferramentas para que as interações cognitivas se façam em função da construção da epistemologia da instituição, tal como elenca Manson e Rennie (2004), salientando a importância deste processo. 


\section{PRESSUPOSTOS DA COGNIÇÃO E AS FERRAMENTAS DA WEB 2.0: ASPECTOS RELEVANTES NO PROCESSO DE GESTÃO DE IES PRIVADA}

\section{INTERAÇÕES METODOLÓGICAS}

No bojo da problemática elencada, busca-se elucidar os aspectos que convergem aos objetivos deste estudo, sobretudo a partir da utilização de interações sistemáticas e metodológicas que permitam elucidar a proposta de estudo. Neste contexto, com base nas considerações de Souza (et al, 2007), a pesquisa pode ser classificada como uma pesquisa acadêmica, em função de seus aspectos diretamente relacionados com a produção científica amparada pelos princípios da indissociabilidade entre ensino, pesquisa e extensão.

Sob a orientação dos procedimentos técnicos, ainda conforme Souza (et al, 2007), a pesquisa segue a linha da documentação indireta, por meio da utilização de fontes primárias e secundárias, alicerçando os aspectos vinculados à sua natureza, configurando-se como uma pesquisa básica que, de acordo com os autores, preconiza a investigação da problemática sem a intenção de desenvolver um produto, mas sim elucidar aspectos vinculados a compreensão do ambiente.

Quanto aos objetivos, a pesquisa configura-se como descritiva já que, conforme Gil (2002) visa proporcionar uma maior familiaridade com a problemática, fundamentando ações a partir da construção de hipóteses. Destaca-se ainda o aporte descritivo da pesquisa, o qual delimita ações a partir da aplicação de questionários e busca compreender as características de comunidades específicas, tal como elenca Gil (2002).

Quanto aos objetivos, a pesquisa configura-se como descritiva, pois que busca a compreensão de características de comunidades específicas, conforme Gil (2002). Já quanto aos critérios atrelados à abordagem do problema, a pesquisa é predominantemente qualitativa, tendo em vista o seu caráter dinâmico e que busca compreender uma interação ativa entre o sujeito e o mundo real e desenvolvida por meio de um roteiro aplicado na forma de uma entrevista estruturada, tal como cita Souza (et al, 2007), confirmando as assertivas de Mattar (1999). Destaca-se também a feição vinculada às fontes de informação, salientando seu aspecto bibliográfico em função das fontes secundárias.

No que tange seus procedimentos técnicos, de acordo com Souza (et al, 2007), a pesquisa estrutura-se como uma pesquisa ação, já que envolve a participação do autor e dos envolvidos nos processes de elucidação do problema, respeitando as bases do estudo de caso, promovendo uma reflexão sobre as ações que facilitam o processo de gestão de uma instituição de ensino superior privada, com o auxilio das ferramentas da Web 2.0 a partir das 
interações cognitivas dos membros de seu corpo social de uma instituição de ensino superior privada.

\section{ASPECTOS GERAIS DO CENÁRIO DO ENSINO SUPERIOR PRIVADO}

Com base nas assertivas de Garcia (2006), durante muitos anos o ensino superior brasileiro cresceu de maneira confortável em função da grande demanda que havia e das políticas governamentais que permitiram a facilidade de acesso a este segmento de ensino. Porém, o mercado encontra-se em um momento no qual não existem mais as grandes quantidades de alunos e as IES que não possuem planejamento acabam por atuar no mercado preconizando políticas de preço agressivas, em qual o futuro acadêmico é atraído pela política de preço e não pelas características qualitativas da IES.

Urge, neste contexto, os aspectos que permitem compreender o surgimento das vagas ociosas, já que estas são o reflexo da falta de planejamento e da ausência de conhecimento do mercado no qual a IES está inserida, considerando os números que retratam o ensino superior mostram uma realidade preocupante, sobretudo para as IES privadas. Neste caso, os principais indicadores estão relacionados à evolução do numero de IES privadas, do número de cursos em IES privadas, das matrículas nas IES privadas e do número de concluintes em IES privadas.

Sob a égide destas orientações, Garcia (2006) a partir das contribuições de Brasil (2004a), identifica que o aumento das IES aumentou de modo considerável durante o período marcado pelas políticas governamentais de expansão do ensino, as quais permitiram a facilidade de acesso ao segmento, sobretudo ao privado, pelo fato das inúmeras possibilidades de acesso ao ensino. Neste caso, com base nas premissas mercadológicas, nas sete pesquisas efetuadas no período que compreendeu o ano de 1999 até 2007 o retrato é explicito à expansão destas instituições, claramente identificado no Gráfico 2, que possibilita a percepção de que em dez anos o mercado passa a adentrar em uma curva estabilizada e pendendo a descendência, solicitando ações, sobretudo vinculadas aos aspectos gerenciais aplicados ao ensino superior privado. 


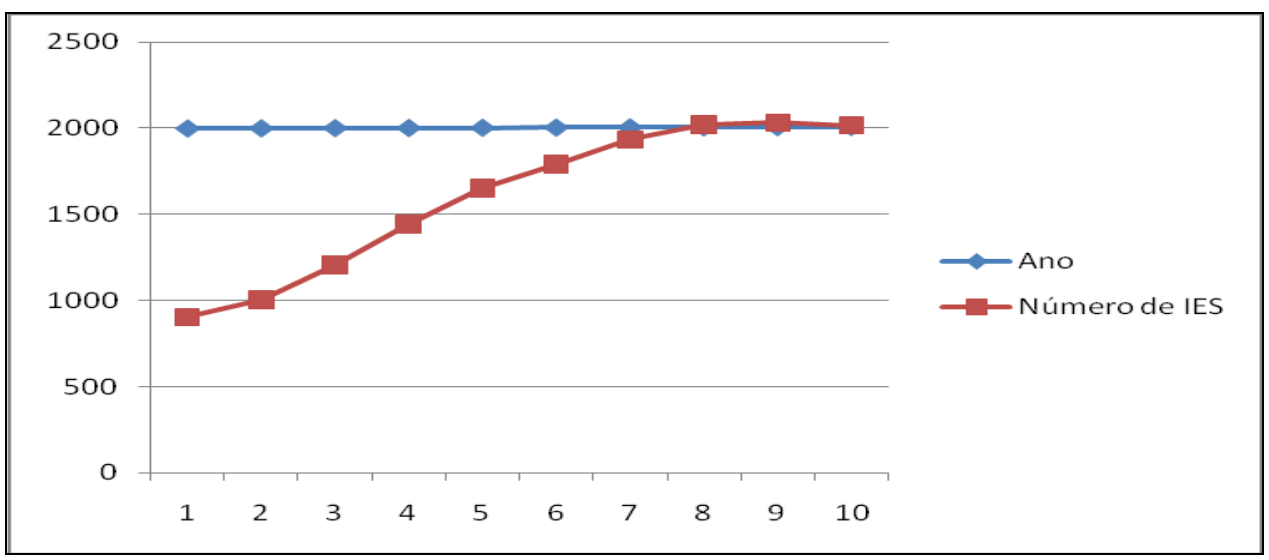

Gráfico 2: Elevação do número de IES privadas no Brasil Fonte: Garcia, 2006, p.25

Ao analisar os dados e de acordo com Garcia (2006) e Demo (2009), fica clara a necessidade de se instituir métodos de discussão e construção de conhecimento gerencial que envolvam o corpo social da instituição, sobretudo a partir da compreensão maiêutica dos principais pontos que permitem acompanhar as mudanças ambientais que acontecem no cenário competitivo destas instituições. Neste caso, alicerçado nas contribuições de Demo (2009), a construção das interações cognitivas no âmbito da instituição podem consolidar a importância de cada agente da instituição, utilizando o conhecimento construído no processo de avaliação institucional e utilizando ferramentas que promovam a participação destes agentes neste processo. Destaca-se, portanto, a utilização das ferramentas da Web 2.0, já que estas se voltam diretamente para o público-alvo das instituições de ensino superior que atuam no mercado privado.

\section{DISCUSSÃO DOS RESULTADOS DA PESQUISA}

A partir das interações metodológicas, a pesquisa delineou-se a partir da percepção dos membros da Comissão Própria de Avaliação de uma instituição privada de ensino superior que segue as premissas estipuladas pelos órgãos reguladores do ensino superior brasileiro a qual, de acordo com Brasil (2004b), representa o corpo social da instituição. Desse modo, esta comissão é composta por dois membros do corpo técnico-administrativo, dois membros do corpo discente e dois membros do corpo docente da instituição, um membro da sociedade civil organizada e dois representantes da mantenedora. Assim sendo, de acordo com os objetivos delimitados, procurou-se identificar alguns indicativos que promovem a 


\section{PRESSUPOSTOS DA COGNIÇÃO E AS FERRAMENTAS DA WEB 2.0: ASPECTOS RELEVANTES NO PROCESSO DE GESTÃO DE IES PRIVADA}

construção de uma epistemologia para o ensino superior privado, ensejado nos dias atuais de acordo com Schlickmann (2009), com o auxílio das interações cognitivas e do uso de Web 2.0 .

O roteiro procurou direcionar as reflexões sobre a relevância das associações cognitivas no processo de gestão institucional, identificando de que modo as ferramentas da Web 2.0 podem contribuir para este processo tendo como marco orientador o processo de avaliação institucional, considerado por Silva (2008) o responsável pela construção de indicadores vinculados ao processo de gestão de uma instituição de ensino superior, destacando quais destas ferramentas podem ser as mais eficazes neste processo já que ele é fundamental para a consolidação da epistemologia no gerenciamento destas instituições. Por fim, as inquirições procuraram identificar a pujança da construção do conhecimento aplicado à gestão da instituição, utilizando-se do processo de associação de conhecimentos e construção de aprendizagem, instruindo ações que consolidem as atividades do corpo social da instituição em prol de seu desenvolvimento.

Por meio das contribuições, as investigações consolidam uma percepção focada nas interações cognitivas, tendo-as como inerentes ao processo de construção do conhecimento e concretização da aprendizagem na gestão de uma instituição de ensino superior, corroborando o que salienta Schlickmann (2009) e permitindo a fundamentação dos processos gerenciais e a compreensão do público-alvo da instituição de seus métodos de abordagem e de comunicação, consolidando as estratégias e reflexões e minimizando os índices de evasão acadêmica.

Assim sendo, com base no novo perfil acadêmico, a utilização de ferramentas que otimizem o processo de comunicação dos resultados obtidos na avaliação é fundamental, destacando-se, portanto, a eficácia das ferramentas da Web 2.0 como afirma Demo (2009) ao salientar os desafios pedagógicos da utilização destas ferramentas.

De acordo com as investigações apresentadas, confirmando o que é posicionado pela Revista Ensino Superior de dezembro de 2009, a utilização destas ferramentas promove a participação do público envolvido no processo, sobretudo no fato de requerer um auxílio profícuo na sistemática de comunicação dos resultados orientando a construção da identidade da instituição. Isso acontece por meio das interações que se voltam a construir o conhecimento institucional e consolidando os aspectos gerenciais e estratégicos da organização, já que as novas tecnologias podem orientar a percepção do mercado e as 


\section{PRESSUPOSTOS DA COGNIÇÃO E AS FERRAMENTAS DA WEB 2.0: ASPECTOS RELEVANTES NO PROCESSO DE GESTÃO DE IES PRIVADA}

estratégias mercadológicas que incidem diretamente no publico desta organização, potencializando a utilização dos resultados da Avaliação.

No prosseguimento das investigações, as premissas cognitivas incitam a estruturação de um conhecimento relevante à gestão e aos processos voltados a cada membro do corpo social da instituição, como afirma Gil (2009), sendo que as ferramentas da Web 2.0 potencializam este processo. Todavia, deve-se salientar, com base nas orientações de Demo (2009), que para a plena utilização destas ferramentas a instituição deve consolidar um processo de conscientização e de inserção tecnológica perante aos segmentos que compõe sua comunidade acadêmica. Assim sendo, colima-se o fato descrito pela Revista Ensino Superior de dezembro de 2009, tendo por certo de que a promoção da reflexão em relação ao que é discutido e no que tange a abrangência da ferramenta, destacam-se as redes sociais, os blogs, os e-books, as ferramentas de wiki, os fóruns e os Rss Fedds.

A partir da utilização das ferramentas da Web 2.0, as associações cognitivas tem-se por base o processo de interação mental a partir da junção de conhecimentos que geram a aprendizagem preconizada em função dos objetivos. Estas ferramentas, neste contexto, promovem a construção do conhecimento necessário à consolidação dos processos de gestão institucional, sobretudo pelo fato do envolvimento de todos os segmentos do corpo social da instituição, tal qual afirma Demo (2009) e Hargadon (2008), salientando que este procedimento deve obedecer aos processos vinculados ao bom uso destes insumos, já que a utilização destas ferramentas incita o processo de interação cognitiva que é responsáveis pela produção do conhecimento e do processo de aprendizagem.

Assim sendo, com a utilização das ferramentas da Web 2.0 no contexto das interações cognitivas, ocorre a possibilidade de comunicar a orientar o processo de gestão a partir da influência mútua dos segmentos do corpo social da instituição construindo uma sensibilização orientada à gestão e aos indicadores do processo de avaliação institucional, por meio da credibilidade necessária gerada a partir da utilização consciente e correta destas ferramentas, vencendo, tal como afirma Demo (2009), os desafios institucionais desta utilização.

\section{CONCLUSÃO}

As instituições de ensino superior tornam-se necessárias ao entorno em função de suas estratégias voltadas à construção do conhecimento e a preparação de insumos intelectuais 


\section{PRESSUPOSTOS DA COGNIÇÃO E AS FERRAMENTAS DA WEB 2.0: ASPECTOS RELEVANTES NO PROCESSO DE GESTÃO DE IES PRIVADA}

inerentes ao desenvolvimento da sociedade. Seja qual for seu principal atributo, este sempre estará relacionado às interações cognitivas, já que estas permitem compreender os desafios apresentados pelo mercado, as prerrogativas da capacitação e qualificação de mão-de-obra e, sobretudo, ao processo de constituição de novas competências construindo e consolidando os objetivos estratégicos, os quais constroem parâmetros norteadores para seu desenvolvimento.

A utilização das ferramentas da Web 2.0, neste contexto, permite que a comunicação dos resultados da avaliação institucional aconteça de modo eficaz e profícuo, promovendo conhecimentos inerentes ao desenvolvimento estrutural e cognitivo dos processos gerenciais e pedagógicos desta organização. Desse modo, delineando os aspectos que permitam a construção de uma epistemologia gerencial que posiciona a identidade institucional deste órgão, sobretudo pelo fato das reflexões orientadas em meio ao corpo social da instituição.

Por meio do pressuposto, baseado na importância da construção do conhecimento no âmbito institucional, é possível concluir que as interações cognitivas são possíveis e contribuem de modo direto no processo de gestão institucional, sobretudo pela observância dos indicadores vinculados ao processo de avaliação institucional. Sob estas orientações, conclui-se ainda que a utilização das ferramentas da Web 2.0 qualifica o processo de comunicação dos resultados da avaliação, especificamente pelo fato de promover uma discussão relacionada à identidade institucional em um ambiente de interação com o público alvo da instituição e com os membros de seu corpo social, destacando a utilização de redes sociais, os blogs, os e-books, as ferramentas de wiki, os fóruns e os Rss Fedds.

No bojo da utilização destas ferramentas, destaca-se a necessidade de uma conscientização aplicada ao processo deste emprego, vencendo os desafios institucionais inerentes, qualificando as interações cognitivas que permitem compreender a identidade e o âmbito de atuação desta instituição, construindo um conhecimento em relação à perspectiva mercadológica para este segmento. Assim sendo, orientando o processo de gestão a partir da interação com todos os segmentos do corpo social da instituição e atividades a partir de processos de sensibilização orientados à gestão e direcionados a elucidar os indicadores avaliação institucional, instaurando a credibilidade no processo, sobretudo pelo fato da plena utilização de seus resultados e das reflexões promovidas a partir da comunicação eficaz de todo o processo a partir da Web 2.0.

Rev. GUAL., Florianópolis, v.4, n. 1, p.01-26, jan/abr. 2011 


\section{PRESSUPOSTOS DA COGNIÇÃO E AS FERRAMENTAS DA WEB 2.0: ASPECTOS RELEVANTES NO PROCESSO DE GESTÃO DE IES PRIVADA}

A pesquisa corrobora o que se fundamentou no referencial teórico, já que por meio das investigações foram apresentadas as premissas cognitivas e suas interações vinculadas à construção do conhecimento e dos processos de aprendizagem, sobretudo em um segmento carente de informações e investigações que busquem elucidar os aspectos inerentes à construção de uma epistemologia gerencial para o ensino superior privado. Destaca-se ainda que, por meio destes pressupostos, a interação tecnológica com as ferramentas da Web 2.0 consolida a comunicação eficaz dos resultados avaliativos da instituição e promovem uma reflexão orientada a gestão institucional com base nos processos de conscientização aplicados ao seu corpo social.

Por meio do referencial bibliográfico e das investigações, conclui-se que as interações cognitivas facilitam a utilização das ferramentas da Web 2.0 já que permitem a construção do conhecimento gerencial a uma reflexão orientada pelos membros de seu corpo social da instituição em busca de uma epistemologia de gestão. Assim sendo, evidenciando o compromisso sociabilizado em relação à participação no processo de avaliação institucional, já que esta é fundamental na construção da identidade institucional, e promovendo indicadores que demonstram a sensibilização do corpo social em relação à utilização das principais ferramentas e à orientação no que tange os processos gerenciais voltados a uma epistemologia gerencial no ensino superior privado.

\section{REFERÊNCIAS}

ACAFE. Avaliação Institucional para as IES do sistema ACAFE. Sistema ACAFE: Florianópolis, 2005.

ANDERSON, L.W,; KRATHOWHOL, D.R. et al. (Ed.) A taxonomy for learning, teaching, and assessing: a revision of bloom's taxonomy of educational objectives. New York: Longman, 2001.

BEDNAR, A.; CUNNINGHAM, D.; DUFFY,T. PERRY, D. Theory into practice: how do welink. In T. Duffy \& D. Jonassen (Eds.), Constructivism and the Technology of Instruction: a Conversation. New Jersey: Lawrence Erlbaum Associates, 1992.

BLOOM, B. S.; KRATHWOHL, D. R. \& M., B. B. Taxonomia de objetivos educacionais: domínio afetivo. Porto Alegre: Globo, 1973.

BRAGA, Ryon. Análise setorial do ensino superior privado no Brasil: tendências e perspectivas 2006 - 2010. São Paulo: Hoper. 2005. 
BRASIL, CONAES. Diretrizes para a Avaliação das Instituições de Educação Superior. Brasília: 2004a.

BRASIL, Presidência da Republica. Lei 10.861, de 14 de Abril de 2004. Disponível em: http://portal.mec.gov.br/arquivos/pdf/leisinaes.pdf. Brasília: 2004b.

BRASIL, INEP. SINAES - Sistema Nacional de Avaliação da Educação Superior. 3 ed. Brasilia 2006.

BRASIL, MEC. Portaria Normativa No 12 de 5 de setembro de 2008. Disponível em: http://www.unicerp.edu.br/ensino/editais/cpa/PORTARIA_NORMATIVA_12\%20\%20IGC\% 2005_09_2008.pdf. 2008.

BRASIL, MEC. Portaria Normativa No 821 de 24 de agosto de 2009. Disponível em: http://www.planalto.gov.br/ccivil_03/Leis/L9394.htm. 2009.

BROW J.S.; DUGUID,P. The social life of information. Boston: Havard Business School, 2000 .

CARLAINER, S; SHANK, P. (Eds.). The e-learning handbook: past promises, present challenges. New York: Pfeiffer, 2008.

CASTAÑO, C. (1994). La investigacion en medios y materiales de ensenanza. In J. Sancho (Coord.), Para una Tecnologia Educativa. Barcelona: Horsori, pp. 269- 295.

CLARK, Richard E. \& SUGRUE, Brenda M. (1991). Research on instructional media. In G. Anglin (Ed.), Instructional Technology: Past, Present and Future. Englewood: Libraries Unlimited, pp. 327-343.

COUTINHO, C. A influência das teorias cognitivas na investigação em Tecnologia Educativa. Pressupostos teóricos e metodológicos, expectativas e resultados (1985-2000). Braga: CIEd,Universidade do Minho 2005.

COUTINHO, C. A investigação em "meios de ensino" entre 1950 e 1980: expectativas e resultados. Revista Portuguesa de Educação, n. ${ }^{\circ} 19$ (1), pp. 153-174. 2006.

DEMO, P. Educação Hoje - Novas tecnológicas, pressões e oportunidades. 1ed. Atlas. São Paulo: 2009.

EDELMAN, G. M.; TONONI, G.A. A universe of consciousness: how matter becomes imagination. New York: Basci Books, 2000.

FACHIN, G.R.B; STUMM, J.; COMARELLA, R. L.; SANTOS, Neri; FIALHO, F. A.P. Gestão do Conhecimento e a visão cognitiva dos repositórios institucionais, p.220 - 236. Revista Perspectivas em Ciência da Informação vol.14, n.2. Maio/ago 2009. 


\section{PRESSUPOSTOS DA COGNIÇÃO E AS FERRAMENTAS DA WEB 2.0: ASPECTOS RELEVANTES NO PROCESSO DE GESTÃO DE IES PRIVADA}

FIALHO, F. A.P. Ciências da Cognição. Florianópolis/SC: [s/n], . No prelo. 2006.

FRANCISCO, T. H. A.; OTANI, N; AMIM, E.H.F.; MELO, P.A de.; ANGELOTTI, R. A identificação das core competences da FACIERC com base na percepção de seus gestores. Anais do IX Colóquio Internacional sobre gestão universitária na América do Sul . Florianópolis, 2009, CD ROM.

GARCIA, M. Gestão Profissional em Instituições Privadas de Ensino Superior - Um Guia de sobrevivência para mantenedores, acionistas, reitores, pró-reitores, diretores, coordenadores, gerentes e outros gestores institucionais. 1 ed. São Paulo: Hoper 2006.

GIL, A.C. Didática e Metodologia do Ensino Superior. São Paulo, Atlas. 2009.

GIL, A.C. Métodos e técnicas de pesquisa social. 5 ed. São Paulo: Atlas, 1999.

HARGADON, S.Web 2.0 is the future od education. 2008, Disponível em :

http://www.stevehargdon.com/2008/07/web-20-is-future-of-education-talk.html.

RISTOFF, D. I. A expansão do ensino superior e as políticas de democratização do ensino desenvolvidas pelo governo atual. In: IX Colóquio Internacional sobre gestão universitária na América do Sul. Instituto de Pesquisas em Administração Universitária da Universidade Federal de Santa Catarina. Florianópolis, 2009.

INEP/MEC. Censo da Educação Superior 2008. Brasília: Ministério da Educação, 2009.

JACOB, E.K.; SHAW, D. Sociocognitive perpectives on representation. Annual Review of Information Science and Technology, v. 33, p.131-183, 1998.

LIMA, G.A.B. Interfaces entre a ciência da informação e ciência cognitiva. Ci. Info., v. 32, n. 1, p.77-87, jan./abr. 2003. Disponível em:

$<$ http://www.ibict.br/cienciadainformacao/viewarticle.php?id=166\&layout=abstract $>$. Acesso em: 25 fevereiro 2010.

MACHADO, L. E.. Gestão Estratégica para instituições de ensino superior privadas. 1 ed. - São Paul: FGV Editora 2008.

MANSON, R.; RENNIE, F. Connection: learning for the connected generation. New York: Information Age Publishing, 2004.

, E-learning and social networking handbook: resources for higher education.

London: Routledge, 2008.

MATTAR, F. N. Pesquisa de Marketing: metodologia e planejamento. $5^{\text {a }}$ ed. - São Paulo: Atlas, 1999.

NEVES, D.A. Information science and human cognition: na information processing aproach. Ci. Inf., v.35, n1, p.39-44, 2006. Disponível em: 
http://www.scielo.br/scielo.php?pid=S0100 - 19652006000100005\&script=sci_arttexrt. Acesso em: 25 de fevereiro 2010.

POZO, J. Teorias Cognitivas del Aprendizage. Madrid: Morata. 1994.

REVISTA ENSINO SUPERIOR. O Conflito de Gerações. São Paulo: Ed. Segmento, 2009. Mensal.

SANTOS, N. Gestão do Conhecimento - Apostila do curso de Pós-Graduação scrictu-senso em Engenharia da Produção. UFSC. Florianópolis 2008.

SAVIANI, D. Pedagogia historic-crítica. Campinas: Autores Associados, 2005.

SCHLICKMANN, R. Administração Universitária: Em Busca De Uma Epistemologia. Anais do IX Colóquio Internacional sobre gestão universitária na América do Sul . Florianópolis, 2009, CD ROM.

SILVA, R.. Balanced Scorecard - BSC - Gestão do Ensino Superior - Gestão Profissionalizada e Qualidade de Ensino para Instituições de Ensino Superior Privado. Jurua Curitiba - 2008 .

SOUZA, A. C.; FIALHO, F.A.P.; OTANI, N.; TCC - Métodos e Técnicas. 1 Ed. Florianópolis: VisualBooks 2007.

VIGNAUX, G. As Ciências Cognitivas. Lisboa: Instituto Piaget. 1991.

WINN, W. \& SNYDER, D. Cognitive perspectives in psychology. In D. Jonassen (Ed.), Handbook of Research for Educational Communications and Technology. New York: Macmillan USA, 1996, pp. 112-141.. 


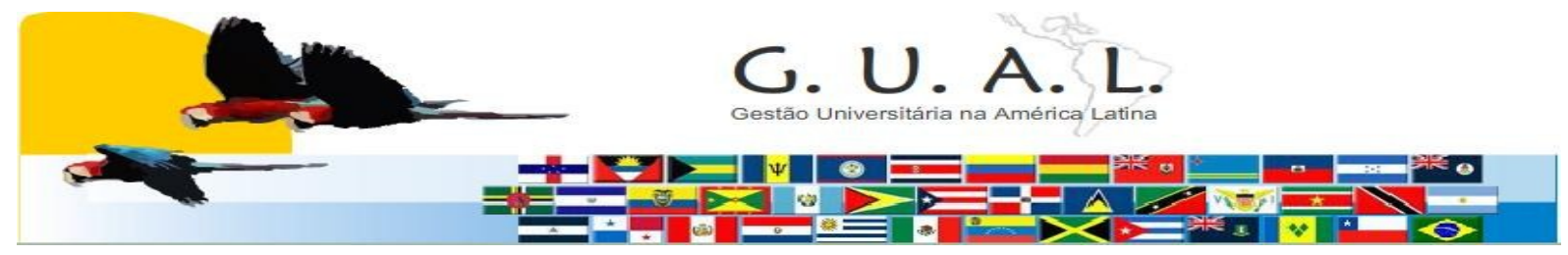

ISSN 1983-4535

\title{
ASSUMPTIONS OF COGNITION AND THE TOOLS OF WEB 2.0: RELEVANT ASPECTS OF MANAGEMENT IN A PRIVATE IES
}

Thiago Henrique Almino Francisco, Specialist thiagohaf@engeplus.com.br

Universidade Federal de Santa Catarina - UFSC

Emillie Michels, Specialist

emillie@fucap.edu.br

Universidade Federal de Santa Catarina - UFSC

\author{
Expedito Michels, Specialist \\ expedito@fucap.edu.br \\ Universidade Federal de Santa Catarina - UFSC \\ Alexandre Moraes Ramos, Doctor \\ amrrms@gmail.com \\ Universidade Federal de Santa Catarina - UFSC
}

\begin{abstract}
This work lecture contextualize how the cognitive interactions may facilitate the use of Web 2.0 tools in the management process of a private institution, aiding the construction of an epistemology management to institutions that operate in this segment. The tour lists theoretical aspects related to cognition and epistemology of its assumptions, and concepts that focus on the understanding of private higher education and institutional assessment as a method of building an institutional identity and also to the use of Web 2.0 tools underlying this process. To this end, an academic research will be developed, implemented, based on direct documentation configured as a basic research and about the objectives, classified as exploratory, predominantly qualitative, classifying it as an action research. To collect the data bases will be considered research-driven structure. The results suggest, among other things, cognitive interactions that facilitate the use of Web 2.0 tools because they allow the construction of a knowledge management oriented reflection by members of his social body of the institution in pursuit of an epistemology based on the processes linked to increased awareness of their academic community.
\end{abstract}

Keywords: Cognition. Higher education. Web 2.0. 